\title{
Multi scale analysis by acoustic emission of damage mechanisms in natural fibre woven fabrics/epoxy composites.
}

\author{
C. Bonnafous $^{1, \mathrm{a}}$, F. Touchard ${ }^{1}$, and L. Chocinski-Arnault ${ }^{1}$ \\ ${ }^{1}$ Institut Pprime, CNRS - ENSMA - Université de Poitiers \\ Département Physique et Mécanique des Matériaux \\ ENSMA - Téléport 2, 1 avenue Clément Ader, BP 40109, F86961 Futuroscope Chassseneuil cedex
}

\begin{abstract}
This paper proposes to develop an experimental program to characterize the type and the development of damage in composite with complex microstructure. A multi-scale analysis by acoustic emission has been developed and applied to hemp fibre woven fabrics/epoxy composite. The experimental program consists of tensile tests performed on single yarn, neat epoxy resin and composite materials to identify their $\mathrm{AE}$ amplitude signatures. A statistical analysis of $\mathrm{AE}$ amplitude signals has been realised and correlated with microscopic observations. Results have enabled to identify three types of damage in composites and their associated AE amplitudes: matrix cracking, interfacial debonding and reinforcement damage and fracture. Tracking of these damage mechanisms in hemp/epoxy composites has been performed to show the process of damage development in natural fibre reinforced composites.
\end{abstract}

\section{INTRODUCTION}

Acoustic emission (AE) technique is well known as a powerful method to analyse damage mechanisms in composites [1-3]. This technique has been widely used on carbon or glass/polyester composites [4-5], carbon or glass/epoxy composites [6-8] or polymer reinforced composites [9]. Moreover, some recent studies introduce $\mathrm{AE}$ technique to analyse the behaviour of natural fibre composites [10-12]. The present work proposes a multi-scale analysis of damage mechanisms in hemp-fibre woven fabric composites by acoustic emission.

Several types of damage occur in composites subjected to mechanical loading such as matrix cracking, delamination and fibre debonding, which lead to the material failure. Each damage mechanism generates a specific AE signal. Various parameters are recorded with acoustic emission, such as amplitude, frequency, energy data or waveform parameters. Some studies use a multivariable data analysis to characterise the development of damage by acoustic emission $[5,8,13]$. Many of them have shown a clear correlation between acoustic emission amplitude and damage mechanisms in composite $[6,14]$. Thence, many authors have developed various AE experimental programs adapted to different materials. For cross-ply laminates, tensile tests on neat resin and [0]n, [45]n and [90]n unidirectional composites had been performed to characterise damage [5,9]. Subsequently, the dominant mode of damage developed in each orientation has been associated to the corresponding

\footnotetext{
a e-mail : claire.bonnafous@1mpm.ensma.fr
} 
AE event amplitude. Damage mechanisms in woven fabric composites are much more complicated than in UD laminates because of the complex meso-structure of woven fabric composites [15-16]. Therefore, many authors have developed additional tests or additional experimental methods to study these composites $[6,7,17]$. For example, Scida et al. [6] have realised bending and shear loading tests to study twill-weave and satin-weave glass/epoxy composites. Lomov et al. [7] have combined acoustic emission and $\mathrm{X}$-ray inspection to identify damage mechanisms in woven fabric carbon/epoxy composites.

This paper presents a method which associates a multi-scale analysis by acoustic emission and microstructural observations to characterize damage mechanisms in hemp-fibre woven fabric composites.

\section{MATERIALS AND EXPERIMENTAL METHODS}

\subsection{Materials}

Composites used in this study were made of EPOLAM 2022 epoxy resin reinforced with hemp yarn fabrics. Reinforcement consists of a $4 / 4$ hemp taffeta-weave fabric in which yarns can be characterized by a linear density of 83 tex $(\mathrm{g} / 1000 \mathrm{~m})$. The fibre volume fraction of composites is about 0.4 and the stacking sequence is $[0 / 90]_{7}$. Composite plates have been manufactured by VALAGRO (Poitiers-France), with resin injection moulding technique. Woven fabric composites and neat epoxy resin were processed with identical optimised heating procedure $(24 \mathrm{~h}$ at room temperature, $4 \mathrm{~h}$ at $50^{\circ} \mathrm{C}, 2 \mathrm{~h}$ at $80^{\circ} \mathrm{C}$ and $4 \mathrm{~h}$ at $100^{\circ} \mathrm{C}$ ) [18]. After these processing conditions, the glass transition temperature of the epoxy resin is about $85^{\circ} \mathrm{C}$. The microstructure of the composites is based on four different scales: fibre, yarn, ply and composite scales (Fig. 1). Natural fibres are aggregates of several natural fibre cells glued together in bundles by pectin [19]. The complex microstructure of hemp yarns results from the twist of numerous fibres together. The mean twisting angle has been measured from scanning electron microphotograph of a hemp yarn and estimated about $11^{\circ}$.

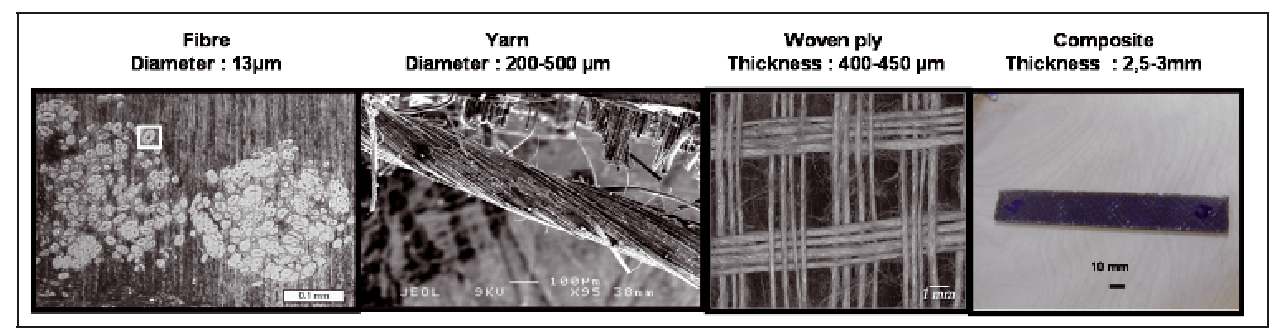

Figure 1. Different scales in the microstructure of hemp-fibre woven fabric/epoxy composite.

\subsection{Yarn tensile test}

Hemp yarns have been tested on an Instron E1000 ElectroPuls testing machine with a load cell of $250 \mathrm{~N}$ and a crosshead speed of $0.5 \mathrm{~mm} / \mathrm{min}$. The specimen gauge length was about $25 \mathrm{~mm}$. To ensure that the yarn was sufficiently clamped during tensile test, two thin glass/epoxy composite end-tabs have been added (Fig. 2). Before testing, the cross-section area of yarn was calculated from the mean diameter by assuming that yarn cross-section is circular. For each sample, it was determined by five optical measurements along the gauge length with a Leica Microsystems optical microscope and the IM 50 software program. 


\subsection{Resin and composite tensile tests}

Composites and neat resin specimens (Fig. 2) were loaded in uniaxial tension on an Instron 4505 testing machine with a crosshead speed of $0.5 \mathrm{~mm} / \mathrm{min}$. Strain was measured by an extensometer centered on one side of the tested specimen. Fracture surfaces were analysed with a Jeol 6400 scanning electron microscope (SEM).

\subsection{Acoustic emission}

For each material, during tensile tests, AE events have been recorded with a PCI-2 acoustic emission system (Physical Acoustics Corporation). AE signals were detected through wide band sensors with a resonant frequency at $300 \mathrm{kHz}$ and an active surface diameter of $10 \mathrm{~mm}$. For each test, the sensor output was amplified by $40 \mathrm{~dB}$ and a bandwidth of $1 \mathrm{kHz}-3 \mathrm{MHz}$ was used. The threshold level was set up as $50 \mathrm{~dB}$ for composites and single yarn, and as $25 \mathrm{~dB}$ for matrix. The system timing parameters were: $200 \mu \mathrm{s}$ for the peak definition time to enable the determination of the AE waveform maximum, $800 \mu \mathrm{s}$ for the hit definition time to enable the system to determine the end of the hit, $1000 \mu \mathrm{s}$ for the hit lockout time to inhibit the measurement of reflections and late-arriving parts of the $\mathrm{AE}$ signals.

A specific grease was used to ensure the contact between sensors and specimen surface. The sensors were fixed with clips directly on resin and composite specimen surfaces and on the glass/epoxy composite end-tabs for yarn tensile tests (Fig. 2). Before tensile testing, the data acquisition system was calibrated for each kind of sample, according to pencil lead breaks. The wave velocity was deduced from the distance between the two sensors and used in the software to locate the events. Thus, only the events located between the two sensors (hatched area in Fig. 2) were recorded.

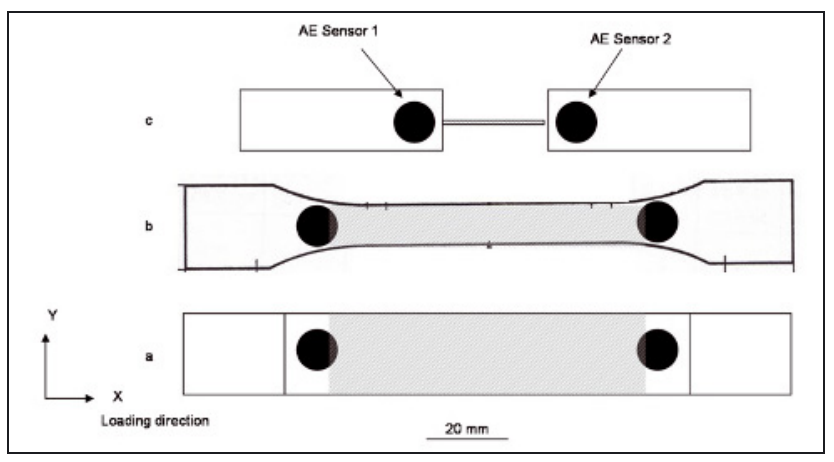

Figure 2. Specimen geometry with AE sensors for: (a) hemp/epoxy composite, (b) neat epoxy resin, (c) single hemp yarn.

\section{RESULTS AND DISCUSSION}

\subsection{Multi-scale analysis in hemp/epoxy composites}

A multi-scale analysis of $\mathrm{AE}$ event amplitude was developed. The acoustic signature of each material -neat resin, hemp yarn and hemp/epoxy composite $[0 / 90]_{7}$ - has been characterised thanks to tensile tests with AE recording performed on sets of specimens. The number of events by amplitude recorded on a set of specimens has been averaged to create an experimental curve of the AE event amplitude distribution for each material. Then, a statistical Laplace-Gauss model was used to fit the AE experimental curves. Two parameters of the Laplace-Gauss model were studied: the mode, which represents the population mean, and the range, which is the full width at half maximum (Fig. $3)$. 


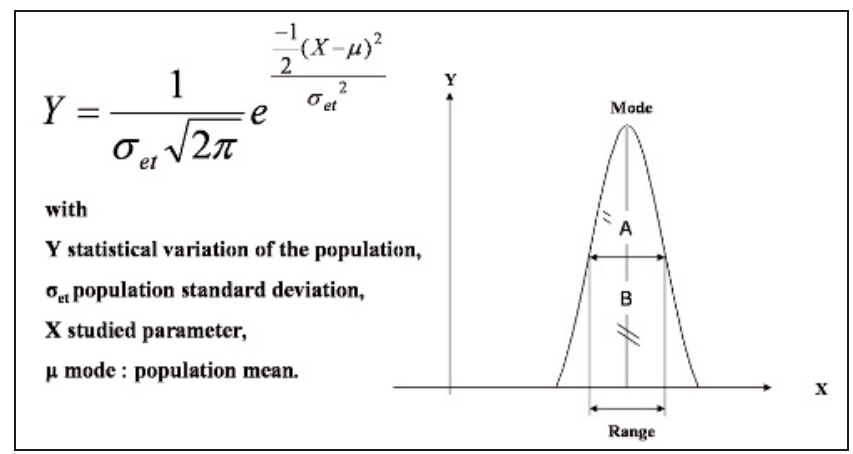

Figure 3. Characteristic parameters in Laplace-Gauss model [20]

Figure 4 shows the experimental curves of the AE event amplitude distribution and the corresponding statistical law for each material. The number of specimens tested for each material depends on the results reproducibility and is indicated on each experimental curve (Fig. 4). Four hemp yarns (Fig. 4a), five specimens of neat resin (Fig. 4b) and thirteen specimens of hemp/epoxy composites (Fig. 4c) have been tested to create the corresponding averaged experimental curve. Figure 4a shows that, for hemp yarn, the AE event amplitude distribution is well fitted with a Laplace-Gauss model. The mode for AE event amplitude distribution of hemp yarn is $69 \pm 9 \mathrm{~dB}$ and the range is between $58 \mathrm{~dB}$ and $79 \mathrm{~dB}$. The events recorded in hemp yarns can be associated with damage such as fibre fractures.

For the epoxy resin, the mode, determined from the Laplace-Gauss fitting, is $47 \pm 8 \mathrm{~dB}$ and the range is between 35 and $58 \mathrm{~dB}$. These parameters characterise major damage mechanisms in resin i.e. initiation and propagation of cracks [21].

The experimental AE amplitude curve obtained for hemp/epoxy woven fabric composites is shown in Figure 4c. Three different Laplace-Gauss laws were necessary to fit the experimental AE amplitude distribution of the composite. Results in Figure 4c show three different modes located at $53 \pm 3 \mathrm{~dB}, 59 \pm 5 \mathrm{~dB}$ and $68 \pm 4 \mathrm{~dB}$ with their corresponding ranges: 50 and $57 \mathrm{~dB}, 54$ and $65 \mathrm{~dB}$ and 64 and $73 \mathrm{~dB}$ respectively.

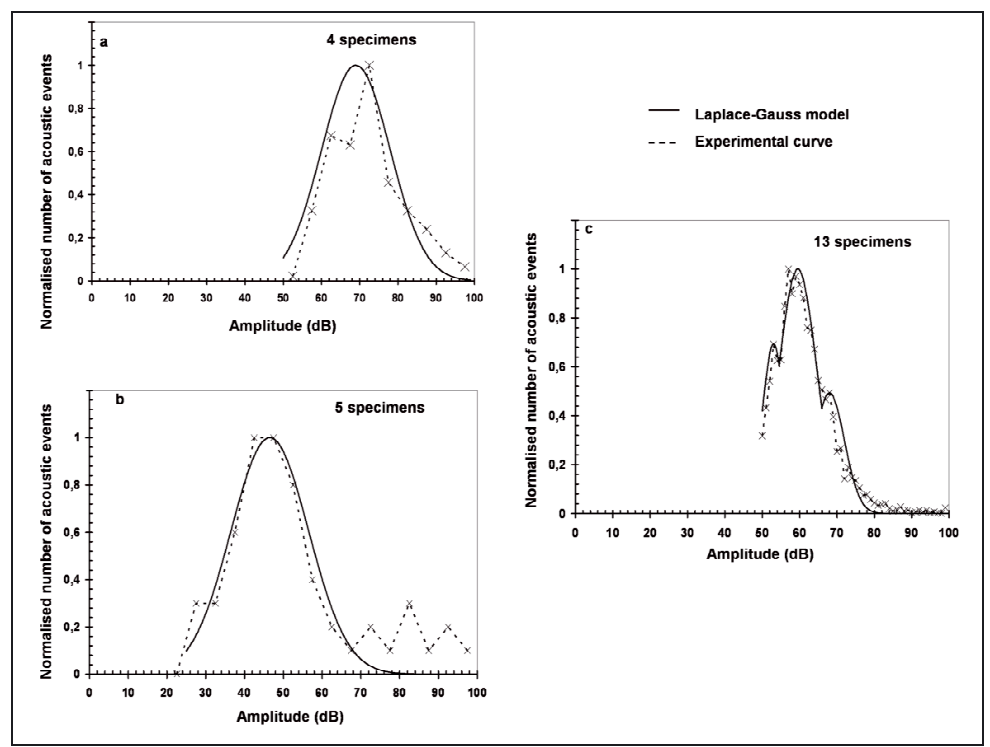

Figure 4. Experimental and statistical curves of the AE event amplitude distributions in: a) hemp yarn b) neat resin c) hemp/epoxy $[0 / 90]_{7}$ composites. 


\subsection{Identification of damage mechanisms in hemp/epoxy composites}

As previously mentioned, the experimental curve of AE amplitude in hemp/epoxy composite shows three peaks. The Figure 5 exhibits the comparison between the experimental and statistical curves for the composite and the statistical curves relative to the neat resin and the single hemp yarn. The first peak recorded in the composite corresponds to the mode of the neat resin $(53 \pm 3 \mathrm{vs} .47 \pm 8 \mathrm{~dB})$ and the third peak is very close to the hemp yarn one ( $68 \pm 4$ vs. $69 \pm 9 \mathrm{~dB})$. These results reveal that AE amplitude signatures of neat resin and single hemp yarn have been found in composite AE amplitude signal; the first peak of the composite can be associated to matrix damage and the third one corresponds to reinforcement damage. It demonstrates the validity of the multi-scale characterisation method developed in this study.

In order to identify the second peak relative to the composite, with a mode at $59 \pm 5 \mathrm{~dB}$, composite fracture surfaces have been observed by SEM. Three types of damage can be seen (Fig. 6):

- in reinforcement: partial fibre fracture in yarn and yarn fracture ( Fig. 6.1a and Fig. 6.1b) ;

- in matrix: matrix cracking and matrix fracture area (Fig. 6.2a and Fig. 6.2b) ;

- $\quad$ at the fibre/matrix interface: partial or complete yarn debonding ( Fig 6.3a, 6.3b and Fig. 6.3c).

It can be noticed that no delamination has been observed; it can be explained by the woven fabric composite architecture.

Results show that the two first types of damage can be clearly linked to the two peaks observed in the AE curve of the composite, corresponding to the modes of neat resin and single hemp yarn. Thus, from the microscopic observations, the second AE peak of the composite, which is located between those of matrix and reinforcement, can be attributed to interfacial damage mechanisms which represents the larger number of events recorded (Fig. 5).

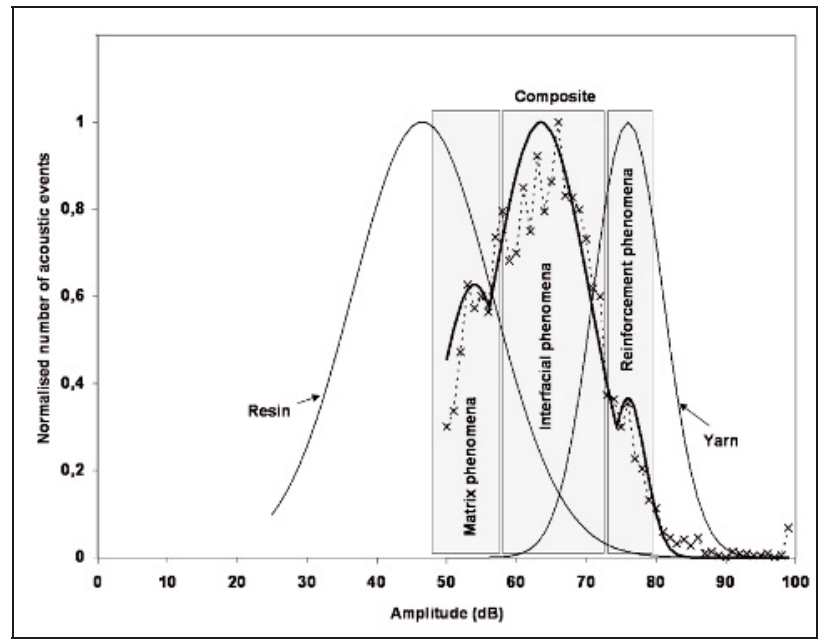

Figure 5. AE event amplitude distributions: experimental and statistical curves of hemp/epoxy $[0 / 90]_{7}$ composites, and statistical curves of single hemp yarn and neat resin. 


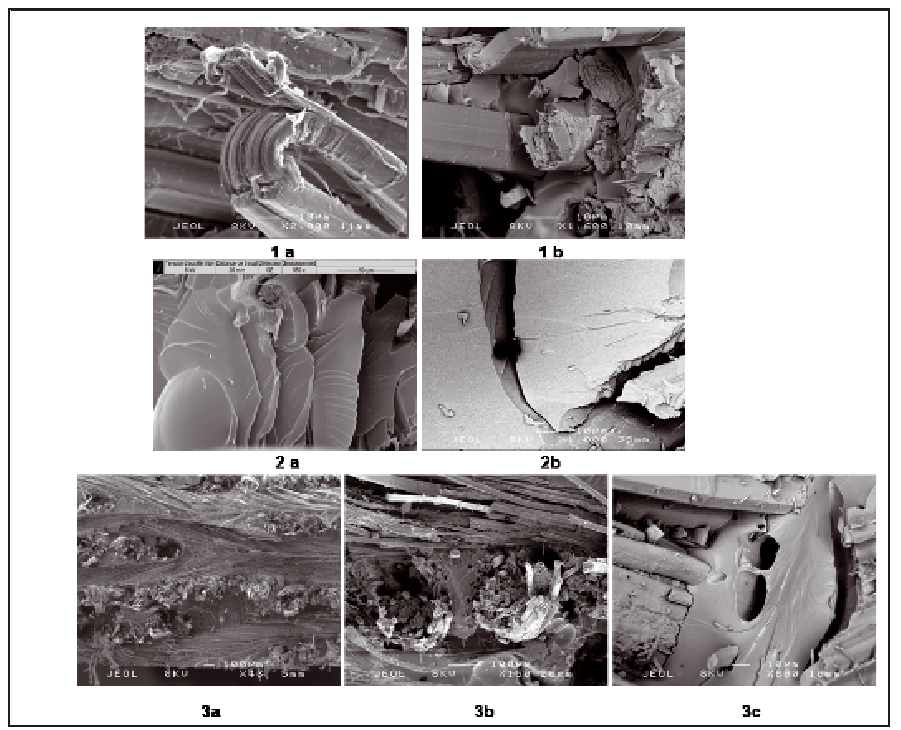

Figure 6. SEM observations of fracture surfaces in hemp-fibre woven fabric composites : damage in hemp yarn reinforcement (1), in matrix (2), and at fibre/matrix interface (3)

Thanks to the multi-scale analysis of AE amplitude signature of composite elementary components, damage mechanisms in woven fabric composites have been characterised.

The different modes and ranges identified and their corresponding damage mechanisms are summarised in Table 1.

Table 1. Mode and range of AE amplitude distribution for each material with the associated damage mechanisms

\begin{tabular}{|c|c|c|c|}
\hline Material & Mode (dB) & Range (dB) & Associated damage mechanism \\
\hline Hemp yam & $69 \pm 9$ & $58-79$ & $\begin{array}{c}\text { Fibre damage } \\
\text { and fracture }\end{array}$ \\
\hline Neat resin & $47 \pm 8$ & $35-58$ & Polymer cracks \\
\hline \multirow{2}{*}{$\begin{array}{c}\text { Hemp /Epoxy } \\
{[0 / 90]_{7}} \\
\text { composites }\end{array}$} & $53 \pm 3$ & $50-57$ & Matrix cracks \\
\cline { 2 - 4 } & $59 \pm 5$ & $54-65$ & $\begin{array}{c}\text { Interface Fracture } \\
\text { Debonding }\end{array}$ \\
\cline { 2 - 4 } & $68 \pm 4$ & $64-73$ & $\begin{array}{c}\text { Reinforcement damage } \\
\text { and fracture }\end{array}$ \\
\hline
\end{tabular}

\subsection{Tracking of damage mechanisms in hemp/epoxy}

$\mathrm{AE}$ events have been recorded throughout composite tensile tests. Figure $7 \mathrm{~b}$ show examples of stress-strain curves with the corresponding AE event cumulative numbers for hemp/epoxy composites. Additional information can be obtained thanks to multi-scale analysis: each type of composite damage mechanism can be followed during tensile tests. Figure 7 a show AE events amplitude versus normalised strain for the composite. The $\mathrm{AE}$ events have been characterised by using different symbols according to the amplitude ranges previously identified (Tab. 1). Therefore, it enables to distinguish three types of damage phenomena occurring in reinforcement, matrix or interface. This allows the partition of the AE events amplitude versus normalised strain curve into distinct areas (Fig. 7.a): three areas can be identified. 
In hemp/epoxy composite, the first area has been defined from 0 to $32 \%$ of the ultimate strain (Fig. 7.a). The figure 7.b shows that the threshold of the curve of the $\mathrm{AE}$ event cumulative number is about $11 \%$ of the ultimate strain. In this first area, events recorded can be associated with the initiation and growth of matrix cracks and with fibre/matrix interface debonding. Then, the second area, from $32 \%$ to $62 \%$ of the ultimate strain (Fig. 7.a), is characterised by AE phenomena linked to interface and reinforcement damage. It corresponds to a slightly increase of AE event number (Fig. 7.b). At the end of the test, in the third area, from $63 \%$ of the ultimate strain, lots of AE events have been recorded; there are simultaneously a large number of events linked to interfacial phenomena and also events for reinforcement and matrix damage (Fig. 7.a). This simultaneous increase in the three types of damage previously identified explains the increase in cumulative AE event number illustrated in Figure 7.b which leads to the composite failure.

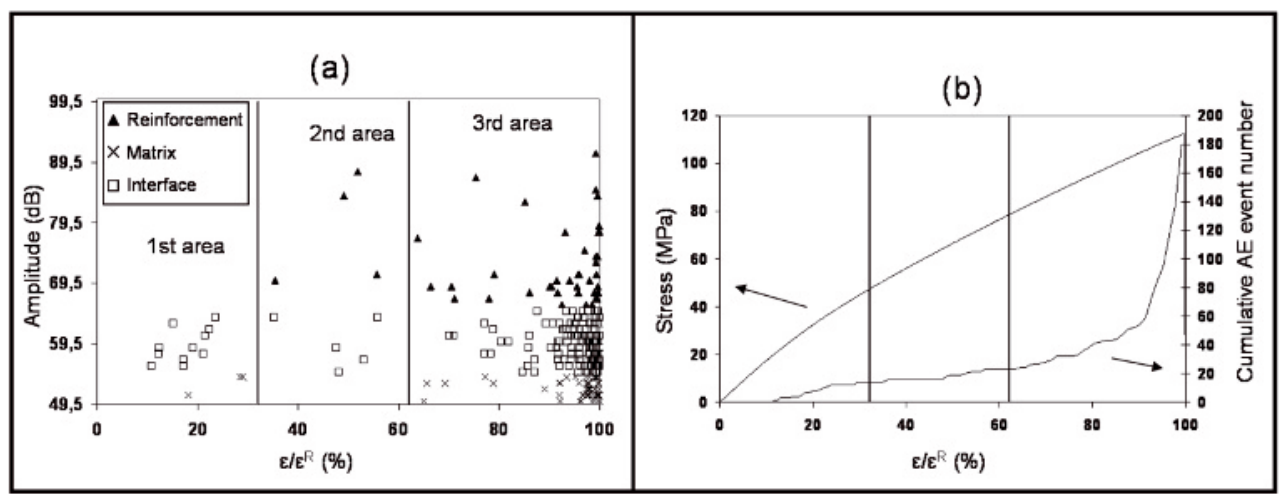

Figure 7. Example of damage mechanism tracking for hemp woven fabric $[0 / 90]_{7}$ composites: (a) stress-strain curves with the cumulative AE event number, (b) AE event amplitude versus normalised strain

Results obtained thanks to the multi-scale analysis of AE event distributions have enabled to identify and follow the development of damage mechanisms in hemp/epoxy composites.

\section{CONCLUSION}

A multi-scale AE analysis has been applied in this study and has allowed the characterization of damage mechanisms in hemp-fibre woven fabric composites. Tensile tests have been performed on single yarns and neat epoxy resin in order to characterise AE amplitude signatures of the elementary components of the composites. A statistical analysis of AE amplitude signals has been realised and correlated with microscopic observations. It has enabled to identify three types of damage in composites: matrix cracking, interfacial debonding and reinforcement degradation with their associated AE events amplitude. These different types of damage have been tracked throughout tests on composite materials. The AE analysis for the different scales of the material combined with microstructural observations have allowed the investigation of the damage development in composite with complex microstructure such as natural fibre woven fabric composites.

\section{Acknowledgements}

The authors thank Région Poitou-Charentes (France) for its financial support and partners of Compochanvre research program.

\section{References}

1. J.M. Berthelot, J. Rhazi, Comp Sci Tech. 37, 411-428 (1990) 
2. A. Rotem, Fibre Sci Tech. 10, 101-121 (1977)

3. M.A. Hamstad, R.L. Moore, J. Comp Mat. 20, 46-66 (1986)

4. M. Giordano, A. Calabrò, C. Esposito, A. D'Amore, L. Nicolais, Comp Sci Tech. 58, 19231928 (1998)

5. S. Huguet, N. Godin, R. Gaertner, L. Salmon, D. Villard, Comp Sci Tech. 62, 1433-1444 (2002)

6. D. Scida, Z. Aboura, M.L. Benzeggagh, Comp Sci Tech. 62, 551-557 (2002)

7. S.V. Lomov, D.S. Ivanov, T.C. Truong, I. Verpoest, F. Baudry, K. Vanden Bosche, H. Xie, Comp Sci Tech. 68, 2340-2349 (2008)

8. W. Haselbach, B. Lauke, Comp Sci Tech. 63, 2155-2162 (2003)

9. X. Zhuang, X. Yan, Comp Sci Tech. 66, 444-449 (2006)

10. J.M. Park, P.G. Kim, J.H. Jang, Z. Wang, B.S. Hwang, K.L. DeVries, Compos: Part B. 39, 1042-1061 (2008)

11. I.M. De Rosa, C. Santulli, F. Sarasini, Compos: Part A. 40, 1456-1469 (2009)

12. T. Czigany, Comp Sci Tech. 66, 3210-3220 (2006)

13. A. Marec, J.H. Thomas, R. El Guerjouma, R, Mech Syst and Sign Proc. 22, 1441-1464 (2008)

14. S. Barré, M.L. Benzeggagh, Comp Sci Tech. 52, 369-376 (1994)

15. X. Tang, J.D. Whitcomb, A.D. Kelkar, J. Tate, Comp Sci Tech. 66, 2580-2590 (2006)

16. F. Edgren, D. Mattsson, L.E. Asp, J. Varna, Comp Sci Tech. 64, 675-692 (2004)

17. G.N. Morscher, Comp Sci Tech, 59, 687-697 (1999)

18. C. Bonnafous, L. Chocinski-Arnault, F. Touchard, C. Dever, 22e congrès sur la déformation des polymères solides (DEPOS 22), France, 77-78 (2009)

19. C. Baley, Compos: Part A. 33, 939-948 (2002)

20. M.R. Spiegel, Les distributions binomiale, normale et de Poisson, Statistique, (Dunod, Paris, 2001)

21. B. Fielder, M. Hojo, S. Ochiai, K. Schulte, M. Ando, Comp Sci Tech. 61, 1615-1624 (2001) 